\title{
Load capacity assessment and strengthening of a railway arch bridge with backfill
}

\begin{tabular}{|r|l|}
\hline Journal: & IABSE Spring Conference 2013 \\
\hline Manuscript ID: & RTM-0110-2013.R1 \\
\hline Theme: & Load carrying capacity and remaining lifetime \\
\hline Date Submitted by the Author: & $\mathrm{n} / \mathrm{a}$ \\
\hline Complete List of Authors: & $\begin{array}{l}\text { Andersson, Andreas; KTH Royal Institute of Technology, Department of } \\
\text { Civil and Architectural Engineering }\end{array}$ \\
\hline Type of Structure: & Bridges \\
\hline Material and Equipment: & Concrete \\
\hline Other Aspects: & $\begin{array}{l}\text { Assessment / Repair, Computational Methods, Instrumentation / } \\
\text { Monitoring }\end{array}$ \\
\hline
\end{tabular}

\section{SCHOLARONE \\ Manuscripts}




\section{Load capacity assessment and strengthening of a railway arch bridge with backfill}

\author{
Andreas ANDERSSON \\ $\mathrm{PhD}$, Researcher \\ KTH Royal Institute of \\ technology (KTH), Stockholm, \\ Sweden adde@kth.se
}

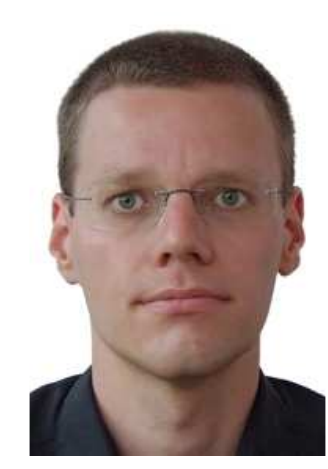

Andreas Andersson, born 1980, received his MSc in Civil Engineering in 2004, Lic Engr. in 2009 and PhD in 2011, all from $\mathrm{KTH}$. He works as an engineer at the Swedish Transport Administration and as a researcher at KTH. His main research areas involve capacity assessment, fatigue assessment and dynamics of bridges using numerical methods and field measurements.

\section{Summary}

In this paper, a load capacity assessment and strengthening measures of a multi-span railway arch bridge with backfill are presented. The bridge is located in Stockholm, Sweden, and constitute a vital link for the national railway network. The bridge consists of 20 concrete arches with overlying backfill, each with a span of $20 \mathrm{~m}$. After more than 80 years of service, severe deterioration of the concrete was found during conditional assessments. A load capacity assessment was performed and the theoretical ultimate load was found to be highly dependent on the development of soil pressures along the arch barrel. The demands from the railway authority are to increase the allowable axle load from 22,5 to 25 tonnes and extend the service life by 50 years. Due to the uncertainties in structural behaviour and progressing degradation, extensive strengthening measures for the arch barrels were decided. To allow for full traffic at all times, the strengthening was performed in stages, to minimize any temporary reduction in load capacity due to removal of existing material. The strengthening was designed using non-linear finite element analysis and each stage of strengthening has been verified using in-situ field measurements.

Key words: concrete arch bridge; backfill; finite element analysis; soil-structure interaction.

\section{Introduction}

Although not commonly built today, arch bridges with overlying backfill constitute an important share of the existing bridge stock in many countries. Most of these bridges were built in the late $19^{\text {th }}$ and early $20^{\text {th }}$ century and are subjected to progressive degradation. For bridges with concrete arch barrels, the material strength rarely conforms to the quality of modern standards. To meet the demands of increasing load intensity and axle loads, capacity assessments are often needed to assure a sufficient level of safety. A great inherent capacity can often be shown by accounting for soil-structure interaction between the arch barrel and the surrounding backfill. Estimates of the ultimate load capacity may however be afflicted with great uncertainties, owing to lack of detailed knowledge of the backfill and great scatter in material strength. For some cases, strengthening may be called for to justify further service of the bridge.

\section{Case study bridge}

In this paper, a case study of a multi-span concrete arch bridge with backfill is presented. The bridge was built in the late 1920's, consisting of 20 concrete arches, one vertical lift span and one steel truss arch. An elevation of the bridge is presented in Fig. 1. The transition between the concrete arches and the steel truss arch is seen in Fig. 2. The total length is $753 \mathrm{~m}$ and was at the time of completion the longest bridge in Sweden. 


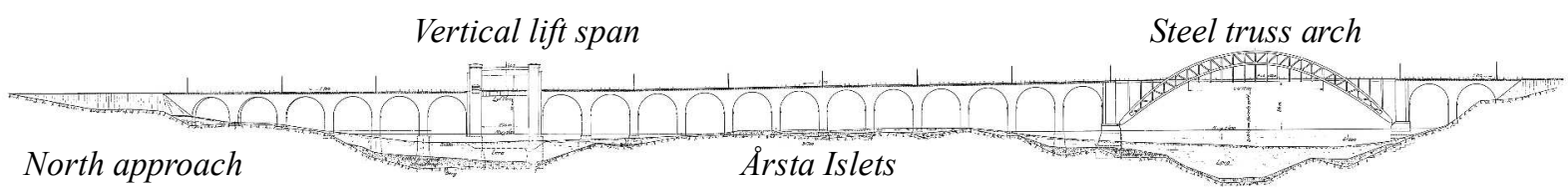

Fig. 1: Elevation of the old Arsta railway bridge.

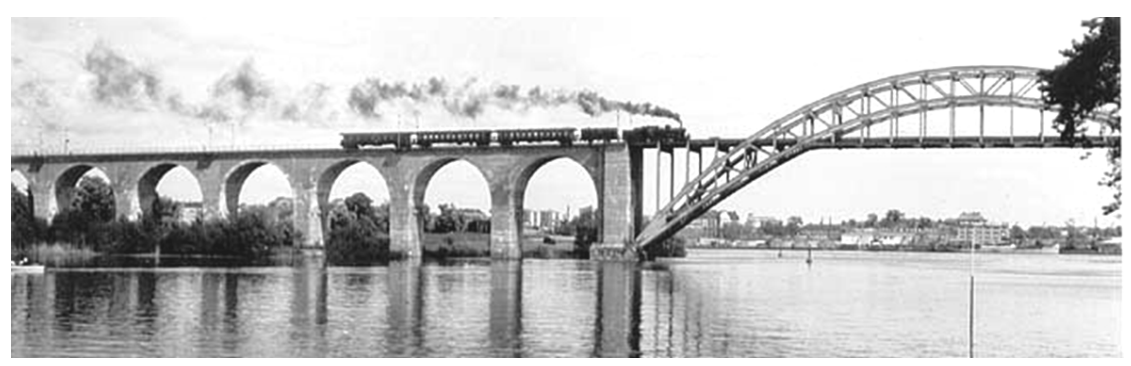

Fig. 2: The old Arsta railway bridge around the 1950's, view from the West.

The concrete arches have a theoretical span of $20 \mathrm{~m}$ and are mainly designed as fixed-end arches. Exceptions are the three arches North of the vertical lift span, designed as three-hinged arches to cope with settlements. The arch barrels have a geometry of a basket arch, consisting of three off centre circles, approximating one-half of an ellipse. A constant radius of $11,3 \mathrm{~m}$ will however make a sufficient approximation of the arch centre line. The thickness of the arch barrel is $0,65 \mathrm{~m}$ at the crown and $1,32 \mathrm{~m}$ at the springing. The bridge is $9 \mathrm{~m}$ wide and carries two railway tracks. The backfill is enclosed by large spandrel walls, illustrated in Fig. 3. The vertical lift span, having a span of $28 \mathrm{~m}$, has not been in service since the 1970's and is nowadays fixed in position. The steel truss arch has a span of $150 \mathrm{~m}$ and a vertical clearance of $26 \mathrm{~m}$ over the navigable channel.

Over the years, the bridge has been the subject of many investigations, conditional assessments and material testing. Repair of parapets and replacement of the drainage system has also been performed. In 2005 and 2006, extensive conditional assessments of the concrete arch barrels were performed, reported in [11] and [12]. Underneath a surface coating of pebble concrete, extensive damages and deterioration of the arch barrels was discovered. Systematic zones of damaged concrete were observed adjacent to cast sections, illustrated in Fig. 3. Testing of 82 concrete core samples reported in [5] resulted in an average compressive strength of $44 \mathrm{MPa}$ but a standard deviation of $18 \mathrm{MPa}$. Many samples were found to have near zero strength. Following the standards in [4], a design compressive strength of merely $6.5 \mathrm{MPa}$ is obtained.

An extensive load capacity assessment was initiated and field measurements were performed for model calibration. The results in [2] showed great uncertainties in estimating the load carrying capacity and a large influence of the confining soil. The former Swedish Railway Administration stated a demand to keep the bridge in service for an additional 50 years and with an increased load carrying capacity from 22,5 tonnes/axle to 25 tonnes/axle. To meet these demands, strengthening of the arch barrels was deemed necessary. Different strengthening measures were developed in [2] and later detailed in [13]. The strengthening was approved by the Swedish Railway Administration, the construction work started in 2007 and is planned to be finalized in early 2013.

\section{Finite element analysis}

In the process of model calibration, pronounced 3D-behaviour of the arch barrels was found. Apart from being a two-track bridge, a large contribution to this behaviour is due to the large concrete spandrel walls. The spandrel walls were not intended to work in composite action with the arch barrels and are separated by an asphalt layer, serving as the original surface coating at the arch 
extrados, Fig. 3. The spandrel walls are also separated by vertical joints at the springing and the crown. Still, the immense stiffness contribution alters the load distribution and structural behaviour. Other studies on masonry arch bridges has also found pronounced three-dimensional behaviour, e.g. [6] and [7]. All FE-analyses are performed using the commercial software SOLVIA03 [14].

\subsection{Reference model}

The primary FE-model used for model calibration and further load capacity assessment is partly presented in Fig. 3. The three-span model consists mainly of 8-noded hexahedral solid elements, except the columns which are modelled as beam elements. The end supports are connected with spring elements corresponding to translational and rotational restraint of adjacent arches. To allow for partial separation, the surface coating is modelled with solid elements, connecting the arch barrel with the backfill and the spandrel walls. Existing reinforcement is modelled with orthotropic shell elements at the arch intrados and extrados. The rail and sleepers are modelled as beam elements and the live load from passing trains are modelled as vertical point loads applied to the rail.

The loading from the field measurements consisted of two locomotives passing the bridge parallel on each track at low speed. The model calibration was performed based on uni-variable analysis and assuming linear material properties and boundaries. A best fit with measured data was obtained using a Young's modulus of $37 \mathrm{GPa}$ for all concrete structures and $100 \mathrm{MPa}$ for the backfill. More details on the models can be found in [1].

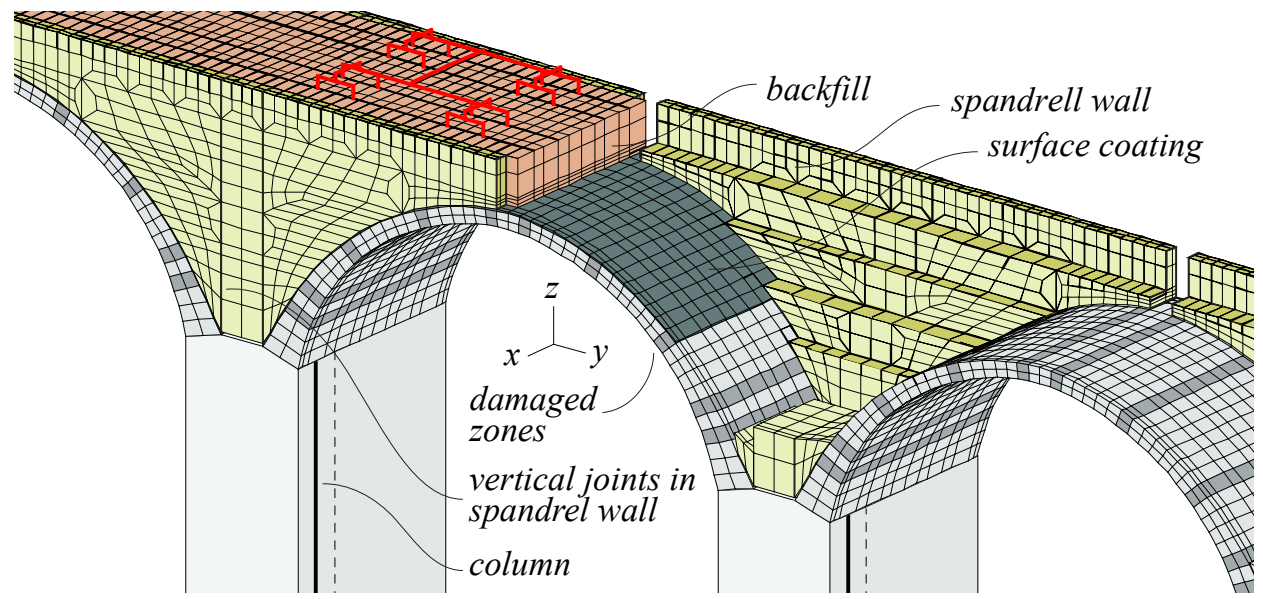

Fig. 3: View of the 3D FE-model, from [1].

\subsection{Semi-linear analysis}

The above presented 3D-model is rather computer demanding to use for extensive parametric studies and load combination algorithms. For this purpose, a global 2D-model of the bridge is instead used. The arch barrels and the columns are modelled with 2D Euler-Bernoulli beam elements, the backfill is modelled with plane stress elements. The steel truss arch is modelled with truss elements and the vertical lift span as beam elements. A more detailed description of the 2Dmodel is presented in [1], a part of the model is presented in Fig. 5.

The 2D-model is used to perform a first estimate of the load carrying capacity and the decisive load positions. The failure criteria is governed by the cross-sectional capacity, governed by combined bending moment and axial thrust, Fig. 4. A somewhat similar method was used by [8] for estimating the load carrying capacity of a multi-span masonry arch bridge. The failure envelope in Fig. 4a is normalized with respect to the cross-section according to Eq. (1). For an unreinforced cross-section, the failure envelope is governed by Eq. (2). When accounting for reinforcement, 
individual failure envelopes are calculated for each cross-section. A linear load function according to Eq. (3) is used, where $\left\{m_{1} ; n_{1}\right\}$ corresponds to the state of permanent load, $\left\{m_{2} ; n_{2}\right\}$ the state when subjected to a reference live load and $\left\{m_{3} ; n_{3}\right\}$ the maximum admissible load. The resulting load factor $\psi \gamma$ is presented in Eq. (4). For an unreinforced cross-section, the intersection of the failure envelope and the linear load function can be expressed in a closed form, for arbitrary reinforcement ratios, numerical interpolation is used.

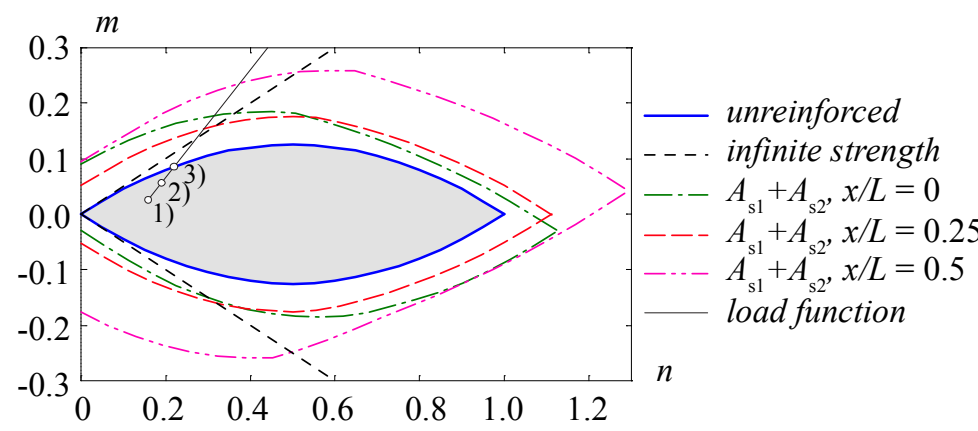

a)

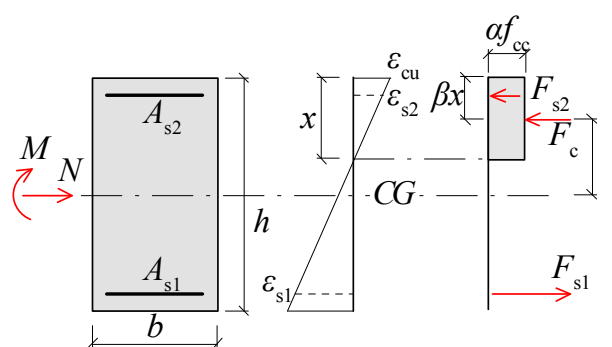

b)

Fig. 4: Principle for cross-sectional capacity, a) failure envelope for combined bending moment and axial force, b) cross-section. Reproduced from [1]

$$
\begin{aligned}
& m=\frac{M}{b \cdot h^{2} \cdot f_{\mathrm{cc}}}, n=\frac{N}{b \cdot h \cdot f_{\mathrm{cc}}} \\
& m(n)=\frac{n}{2}-n^{2} \frac{\beta}{\alpha} \\
& m_{L F}(n)=m_{1}+\frac{m_{2}-m_{1}}{n_{2}-n_{1}}\left(n-n_{1}\right) \\
& \psi \gamma=\frac{n_{3}-n_{1}}{n_{2}-n_{1}}=\frac{m_{3}-m_{1}}{m_{2}-m_{1}}
\end{aligned}
$$

The most unfavourable position of the live load is estimated based on influence line analysis. A total of 100 sections along each arch are evaluated and for each section four live load combinations are tested; maximum positive and negative bending moment with appertaining axial thrust and maximum positive and negative axial thrust with appertaining bending moment. The procedure is automated by algorithms developed in MATLAB. Each load combination from each section is used to calculate an envelope of the load factor $\psi \gamma$. The ultimate load capacity of arches is usually obtained when the structure undergoes a mechanism behaviour, i.e. when forming of a fourth hinge in a single arch. In the above presented semi-linear analysis, a hinge is modelled at each section where the capacity has been reached. The hinge is assumed to have zero bending moment capacity but able to transfer shear force and axial thrust. Assuming the same position of the live load causing the first hinge, the sectional forces are recalculated and additional hinges are formed incrementally. An example of the obtained failure mode is presented in Fig. 5. The method may produce more than four hinges per arch, owing to restraint of the backfill when modelled as linear elastic. The method has been benchmarked in [1] using experimental data reported in [9] and [10], and concluded that the obtained failure load may be non-conservative using the semi-linear method but that the failure load and load position shows good agreement with the experiments. 


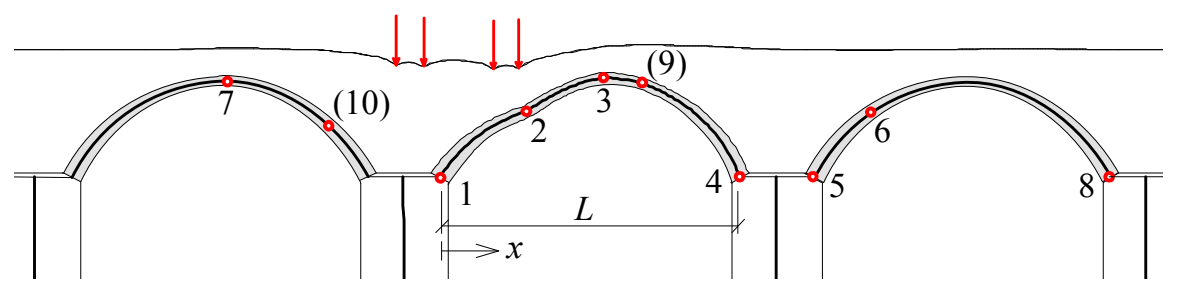

Fig. 5: Forming of hinges in the global 2D-model, train load model D4 at most critical position [1].

\subsection{Nonlinear analysis}

More reliable estimates of the ultimate load capacity have been obtained using material nonlinearity as the failure criterion [1]. For the presented case study bridge, a set of both 2D and 3D models have been analysed. For the 2D-model, both the backfill and the arch barrels are modelled with plane stress elements. Different load positions have been investigated, verifying the position envisaged by the semi-linear method.

The failure criterion for the concrete is governed by a plasticity based tri-axial material model with a smeared crack approach and strain softening. An orthogonal fixed crack method is used. The soil is modelled with a pressure dependent plasticity based model using a Drucker-Prager failure criterion and a cap-model. More detailed information on the material models are found in [14], details on fitted parameters in the present study are found in [1].

An example of the failure mode of the nonlinear 2D-model is presented in Fig. 6. Although undergoing significant cracking, a fully developed hinge is mainly developed at the haunch, point 1 . The overall deformation does however show great similarities with the corresponding semi-linear model, Fig. 5. Due to the axial thrust, arches can normally withstand a significant load level, even if they are unreinforced and have no significant tensile strength. In the present case however, transverse bending, partly due to the large spandrel walls, may induce transverse failure. The transverse capacity is much more dependent on a tensile component, due to the lack of axial thrust.

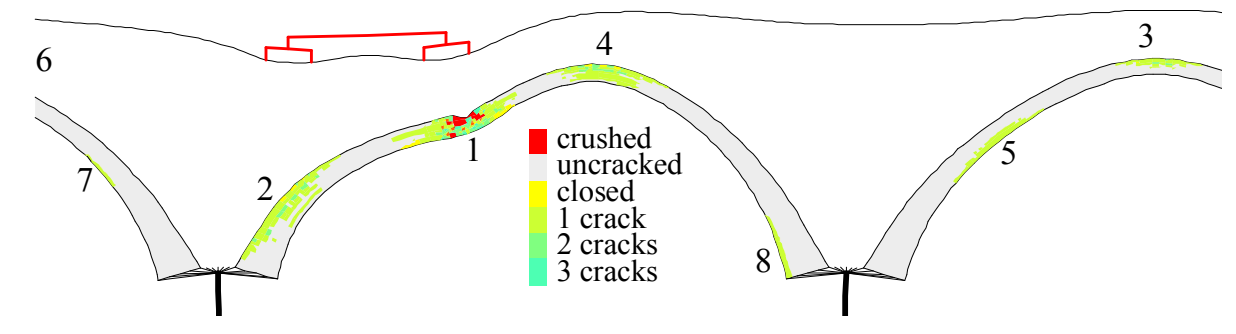

Fig. 6: Concrete cracking and crushing predicted by the three-arch 2D-model, numbers indicate order of first concrete cracking [1].

\section{Strengthening of the arch barrels}

A scenario of an additional 50 years of progressive degradation was used in combination with the nonlinear 3D-model to estimate the ultimate limit state capacity [1]. The concrete was assumed to have a strength corresponding to quality class $\mathrm{C} 12$ [4], with $50 \%$ compressive strength at the damaged zones, Fig. 3. Further, all existing reinforcement was assumed corroded and not contributing to the capacity. The properties of the backfill is found to have a large influence on the capacity but was not accounted for other than as external loading. As a result, a reference model was stated, showing a load capacity that barely fulfils today's load requirements. Due to the large uncertainties in the analysis and estimated properties combined with the future demand on increased load capacity, strengthening of the arch barrels was requested by the bridge owner. 


\subsection{Procedures and models}

A requirement for the strengthening is to maintain the bridge in full service at all time. The bridge is also classified as a historical building, with restrictions in altering its external appearance. The proposed strengthening method involves removal of partly damaged concrete by water blasting and replacement with new reinforced concrete. To minimize the reduction in load carrying capacity, the strengthening was devised in different stages, outlined in Fig. 7. In stage 1 and stage 2, new concrete arch ribs with a width of $250 \mathrm{~mm}$ are cast on each side of the arch barrel. The arch ribs mainly contribute to the longitudinal load capacity, but transverse tendons are post-tensioned to increase the transverse capacity. In stage 3, a new layer of reinforced concrete is cast along the arch intrados. The new concrete has a thickness of $100 \mathrm{~mm}$ and the amount of reinforcement is $\Phi 16 \mathrm{~s} 100 \mathrm{~mm}$ in the longitudinal direction and $\Phi 12 \mathrm{~s} 100 \mathrm{~mm}$ in the transverse direction. The concrete quality corresponds to C32 according to [4]. The final strengthening is not designed to carry the entire live load, but relies on composite action with the original structure.
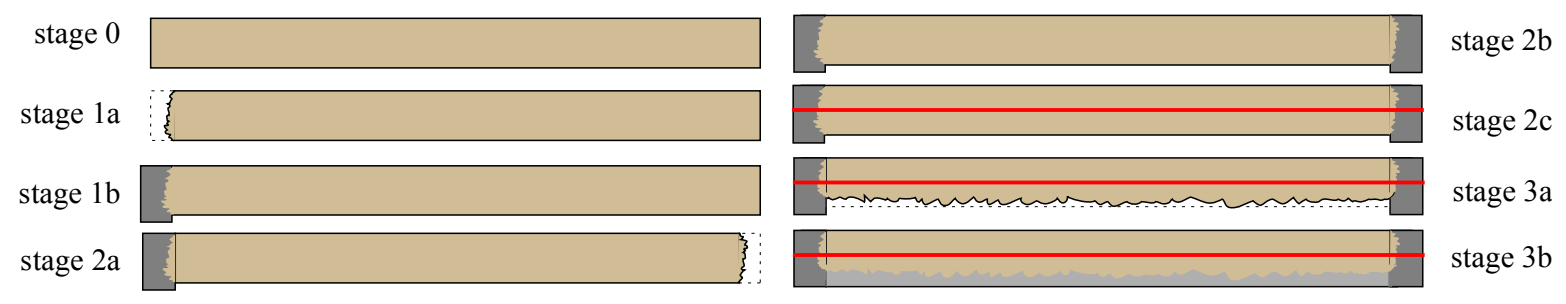

Fig. 7: Cross-section of the arch barrel, illustrating the different stages of strengthening [1].

The strengthening was designed based on nonlinear FE-analysis using the 3D-model with reduced strength parameters as a reference. Each stage of the strengthening was modelled by incrementally removing and adding elements corresponding to water blasting and casting of new concrete. A view of the arch barrel from the FE-analysis is shown in Fig. 8. The arch ribs are modelled as solid elements, the reinforcement in the arch ribs and the tendons are modelled as truss elements. The new concrete on the arch intrados is modelled as orthotropic shell elements. All reinforcement is assigned elasto-plastic material behaviour.

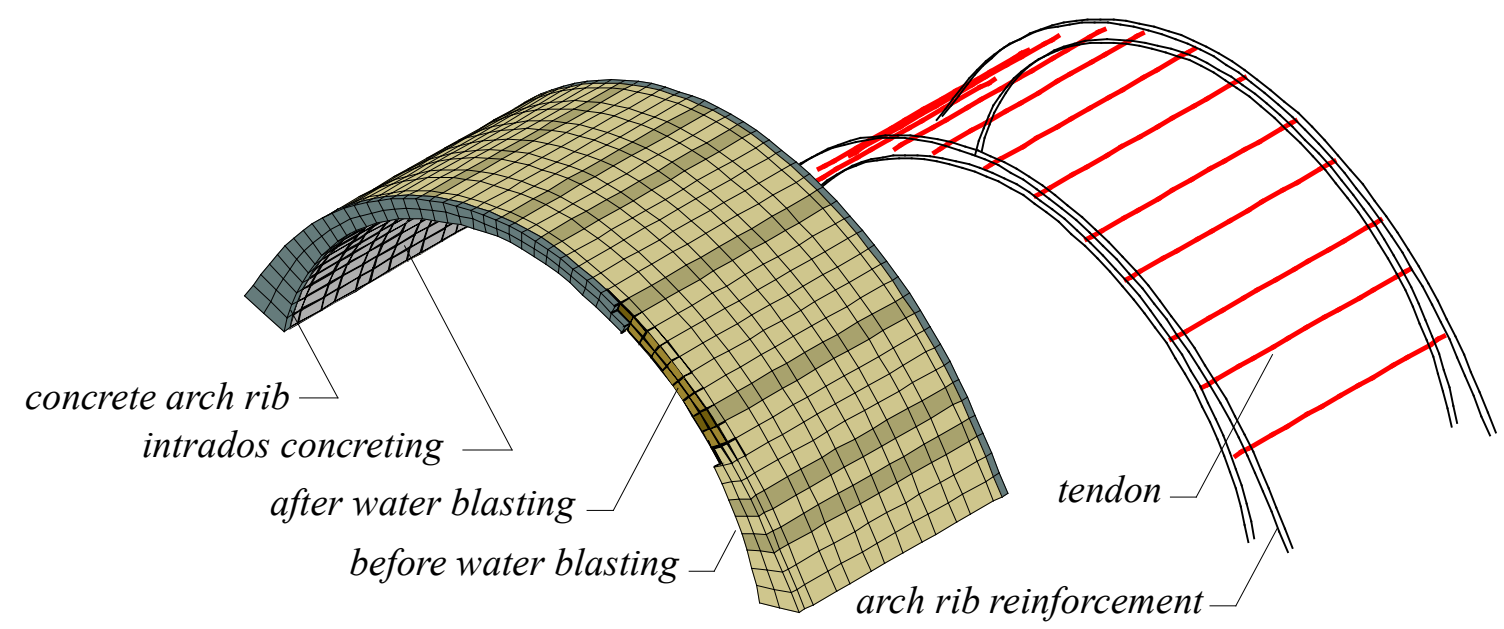

Fig. 8: View of the 3D FE-model for modelling of strengthening stages [1]. 


\subsection{Estimated load capacity}

The load carrying capacity estimated at different stages of strengthening is presented in Table 1, based on the train load model D4, corresponding to a load of $225 \mathrm{kN} /$ axle or a distributed load of $80 \mathrm{kN} / \mathrm{m}$. The corresponding load-displacement curves are presented in Fig. 9, referring to the vertical displacement at the haunch. Before strengthening, a reference load factor $\psi \gamma=1.66$ is obtained. This is to be compared to a demand of 1.3 according to [3]. In the analysis below, the influence of breaking force or temperature has not been accounted for. More extensive load combination algorithms were used in the semi-linear analysis. These results indicated that the breaking force had little influence on the results but that a uniform temperature difference of $+7,5^{\circ} \mathrm{C}$ or $-5,0^{\circ} \mathrm{C}$ could reduce the load factor by up to $25 \%$.

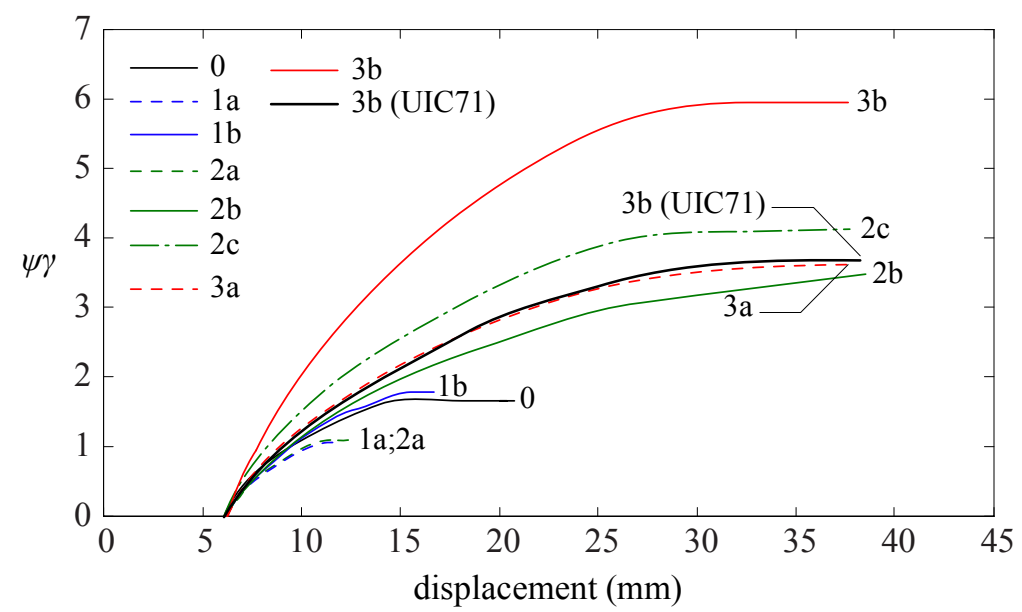

Table 1: Load factors for different stages of strengthening, refers to train load model D4 [1].

\begin{tabular}{ccc}
\hline stage: & $\psi \gamma$ : & diff of ref. \\
\hline 0 & 1,66 & $0 \%$ \\
$1 \mathrm{a}$ & 1,08 & $-35 \%$ \\
$1 \mathrm{~b}$ & 1,77 & $7 \%$ \\
$2 \mathrm{a}$ & 1,09 & $-34 \%$ \\
$2 \mathrm{~b}$ & 3,52 & $112 \%$ \\
$2 \mathrm{c}$ & 4,13 & $149 \%$ \\
$3 \mathrm{a}$ & 3,58 & $116 \%$ \\
$3 \mathrm{~b}$ & 5,94 & $258 \%$ \\
\hline
\end{tabular}

Fig. 9: Load-displacement curves for different stages of strengthening [1].

The lowest load factor below is obtained after water blasting of the edges, resulting in a near 35\% reduction. After installation of the transverse tendons, the load capacity is increased by a factor 2.5 . After casting of the intrados concrete, a load factor of almost 6 is accomplished.

The above results refer to the train load model D4. After strengthening, the target is train load model LM-71, corresponding to a load of $250 \mathrm{kN} /$ axle or $110 \mathrm{kN} / \mathrm{m}$. After stage $3 \mathrm{~b}$, a load factor $\psi \gamma$ $=3.6$ is obtained for load model LM-71.

\section{Conclusions}

In this paper, a load capacity assessment of a multi-span concrete arch bridge with backfill has been presented. Two methods have been used; a semi-linear approach based on cross-sectional capacity and an approach with advanced material nonlinearity for both the concrete and the backfill. The simplified method is suitable to determine critical load positions and load combinations, but may give non-conservative estimates on the ultimate load capacity. A better estimate of the load capacity is instead found using material nonlinearity for both the concrete and the backfill. The development of passive soil pressure against the arch barrel significantly increases the load carrying capacity.

The case study bridge shows pronounced 3D-behaviour, partly due to interaction with the large spandrel walls. Using reduced material strengths, loss of reinforcement and conservative approach on backfill interaction, the analysis fails to meet the demands of future load carrying capacity.

A procedure of segmental strengthening has been proposed, that allows full traffic on the bridge during strengthening and provides a sufficient load carrying capacity after strengthening. This method of strengthening is currently being executed on the bridge and is planned to be finalized in early 2013. 


\section{References}

[1] ANDERSSON, A., "Capacity assessment of arch bridges with backfill, Case of the old Arsta railway bridge", Ph.D. Thesis, Bulletin 107, KTH Royal Institute of Technology, Sweden, 2011.

[2] ANDERSSON, A., "The old Arsta railway bridge, FE-analysis of strengthening of the arch barrels", Report 101 (in Swedish), KTH Royal Institute of Technology, Sweden, 2006.

[3] BANVERKET, "Load capacity assessment of railway bridges", the Swedish Railway Administration, document BVS 583.11, 2005.

[4] BOVERKET. "Boverkets handbook for concrete structures", the Swedish National Board of Housing, Building and Planning, ISBN 91-7147-816-7, 2004.

[5] CBI, "Survey of concrete core samples from the old Arsta bridge", Appendices to report no. 980406 (in Swedish), the Swedish Cement and Concrete Research Institute, 1998.

[6] FANNING, P.J.,BOOTHBY, T.E., "Three-dimensional modelling and full-scale testing of a stone arch bridge", Computers \& Structures, vol. 79, pp. 2645-2662, 2001.

[7] FANNING, P.J.,BOOTHBY, T.E., ROBERTS, B.J., "Longitudinal and transverse effects in masonry arch assessment", Construction and Building Materials, vol. 15, pp. 51-60, 2001.

[8] FELICE, G., "Assessment of the load-carrying capacity of multi-span masonry arch bridges using fibre beam elements", Engineering Structures, Vol. 31, p. 1634-1647, 2009.

[9] MELBOURNE, C., GILBERT, M., "The behaviour of multiring brickwork arch bridges", The Structural Engineer, 73 (3), 1995.

[10] MELBOURNE, C., GILBERT, M., WAGSTAFF, M., "The collapse behaviour of multispan brickwork arch bridges", The Structural Engineer, 75 (17), 1997.

[11] PAULSSON-TRALLA, J., "The old Arsta bridge - Inventory of damages on the arches introdos", Report 7115500:F, Carl Bro AB (in Swedish), 2005.

[12] PAULSSON-TRALLA, J., BJURHOLM, Å., "The old Arsta bridge - Conditional assessment of the concrete arches", Report 7070800, Carl Bro AB (in Swedish), 2005.

[13] PAULSSON-TRALLA, J., "Technical specification and requirements for concrete repair of the old Arsta bridge", Report 7147400:A, Carl Bro AB (in Swedish), 2007.

[14] SOLVIA, "SOLVIA ${ }^{\circledR}$ Finite Element System Version 03”, Report SE 03-1, Users manual, SOLVIA Engineering AB, 2006. 